\title{
HYLAND, Ken \& WONG, Lillian C. L. (Eds.). 2019. Specialised English: New directions in ESP and EAP research and practice. London/New York: Routledge. 260 pp. ISBN: 987-0-138-58877-6
}

Emilia Wassikiewicz-Firlej ${ }^{1}$

The monograph under review is a timely volume opening new vistas in the dynamically developing field of specialised English. It successfully marries original research and practice. Addressing the challenges of the globalising world, the volume explores the themes of commercialisation of education and the domination of English as a medium of academic instruction and presents their impact on English for Specific Purposes (ESP) and English for Academic Purposes (EAP) teaching practice and practitioners. In this context, teaching EAP has been presented as a flourishing business, with a strong ideological underpinning, which enforces certain economically rational forms of instruction, not necessarily aligned with the highest pedagogical standards, and affects the identity and perception of EAP teachers. The publication also delves into the current changes in the status of the English language and the growing role of English as a Lingua Franca (ELF) in professional and academic communication. Several chapters take a closer look at transformations in the modes of communication and the consequent evolution of genres. The uniqueness of this edited

1. Department of Ecolinguistics and Communicology at Adam Mickiewicz University. Poznań - Poland. http://orcid.org/0000-0003-4457-9715. E-mail: emiliawf@amu.edu.pl. 
collection lies in offering a variety of cutting-edge contributions, authored by the crème de la crème of the most distinguished ESP and EAP researchers. Edited by recognised scholars, Ken Hyland and Lillian Won, the collection embraces 17 up-to-the- minute chapters, which have been divided into three sections focusing, respectively, on conceptual issues, texts and practice.

After the preface by Brian Paltridge and the editors' introduction, Part I "Conceptual issues in specialised language use" offers 5 valuable contributions dealing with the core field concepts, embracing ESP, English in the workplace as well as interdiscursivity and power.

The status of English as the global lingua franca of international communication has been well established since the early 2000s (e.g. Jenkins, 2000; Seidlhofer, 2001). Yet, in the opening chapter of the first section of the volume, Anna Mauranen takes a further step and looks at the linguistic outcomes of the language contact, narrowed to the widespread use of ELF in academic contexts, in order to examine how English affects and is affected by other languages. The author approaches the problem from a threefold perspective, embracing the macro level, the cognitive level and the micro social level. Based on the analysis of written and spoken corpora of academic ELF, Mauranen depicts it as a "diffuse, pluricentric and complex contact language" and a "dynamic system" (p. 19), which undergoes constant organisation and reorganisation. As far as the influence of ELF on the English language is concerned, it involves a simultaneous simplification and complexification.

In the next chapter, Jane Lockwood addresses the term "workplace English". In her interpretation, the term is very inclusive as it embraces a variety of workplace contexts, ranging from educational to professional or business ones, and types of users who might be either employed in-service professionals or students still in education preparing for their prospective jobs. Taking into account the globalisation processes, technological revolution and the dynamic growth in the use of Business English as a Lingua Franca (BELF), outnumbering the workplace use of English as the first language (L1), the author calls for "unpacking" the term "workplace English" and theorising it in the pedagogical sense. Consequently, she advances a multilayered analytical framework for workplace English syllabus design (p. 23). The matrix placed in the 
core of the framework illustrates the specificity of workplace English purposes: the horizontal line maps generic to specific purposes, while the vertical axis plots language proficiency to communication performance purposes. The second layer points to the importance of the broad context of workplace communication, catering for multifaceted purposes, contents and audiences, which require different language, register and text choices The matrix is exhibited in a more readerfriendly way in figure 2.2 (p. 27), where it sketches the four quadrants representing "different levels of syllabus work and expertise" (p. 27). The model is then applied to the analysis of four authentic Hong Kong case studies of English courses. The outcomes of the analysis show discrepancies between the needs of the addressees of English courses categorised vaguely as "workplace English", signalling strongly a gap between the reality of workplaces and the classroom and implying closer cooperation between language experts and workplace practitioners.

The gap between academic and workplace use of English is also discussed in the subsequent chapter by one of the world's leading genre theorists Vijay K. Bhatia. The scholar argues that there is a huge gap between what is taught and learnt within English for Professional Communication (EPC) academic courses and the real expectations and requirements of specific practitioners. In his view, however, this gap might be bridged by the integration of EPC teaching and learning with real life professional practices and a focus on professionals' discursive performance. The scholar argues for the application of Critical Genre Analysis to "different forms of EPC programme design activities" (p. 48). This application is exemplified by cases from the legal profession but the author asserts that it can be germane to other disciplines or professions.

A critical stance is also taken by John Flowerdew, yet his paper centres on the notion of power in the academic context and is underpinned with Michel Foucault's ideas. Despite the space limitation, in his paper, Flowerdew manages to discuss multifaceted aspects of power in relation to the university, the EAP teacher, English as a global language, access to the discourse community and discipline, the curriculum and the text (p. 50). The institutional aspects of power and the influence of neoliberal ideology on higher education were already discussed back in the 1990s by Norman Fairclough (1993). Flowerdew's paper echoes this criticism but it is focused on the notion 
of power in EAP context. The author accentuates the ancillary status of EAP as a field and the marginalisation of its practitioners, who have been assigned a subservient role in the academic hierarchy. Fuelled by famous Foucaultian words " $[\mathrm{w}]$ here there is power, there is resistance (Foucault, 1978: 95-96)", Flowerdew calls for greater awareness and recognition of the role and importance of EAP in academia.

In the final chapter of the first part of the volume, Alex Ding points to the dynamic development of EAP as a lucrative business, reflected by a plethora of EAP courses and books available on the market as well as a growing number of EAP teachers employed by universities, and the paradoxical "disarticulation" (p. 64) of EAP instructors' identity. Among other factors, the roots of this identity crisis primarily go back to neoliberal ideology, which had a profound impact on higher education worldwide and led to its commercialisation (cf. Fairclough, 2003; Holborow, 2015). Consequently, taking into account the status of English as a global language, EAP centres have become cash cows for UK universities, yet their staff tends to be perceived as "support workers" (p. 66) and denied adequate academic status, which results in the disintegration of EAP tutors' identity and loyalty to the field and their institution. Undoubtedly, Ding has offered an insightful diagnosis of EAP status but the overall image of the field and its practitioners' identity might be interpreted as overwhelmingly pessimistic. In his attempt to conclude on a positive note, the author, however, emphasises that neoliberal identity options are not deterministic and at the end of the day EAP practitioners have agency, both at the individual and collective level.

Part II of the volume, entitled "Focus on texts", comprises six chapters which take a look at a variety of texts, tracing changes in academic writing from a diachronic perspective, critical thinking in student writing, lexical aspects of spoken academic genres, cultural impact in spoken workplace interactions as well as visual communication in workplace genres and student's personal statements.

The second part opens with a paper authored by Lynne Flowerdew who studies ESP vis-a-vis learner English in order to identify the specificity of both fields and determine the relevant convergences and disparities between them. Drawing on corpus data, she advances 
the application of both corpora research in the disciplinary writing classroom. Being aware of the possible "resistance to ELF on the part of students and teachers", Flowerdew calls for raising students' awareness of this phenomenon, which is pervasive in higher education (p. 88).

In Chapter 7, Ken Hyland reports the results of a diachronic study of persuasion and interaction in academic writing. Based on the analysis of a corpus of academic papers published over the last 50 years and application of his model of stance and engagement, Hyland discusses the discernible transformation of writing conventions across four disciplines (i.e. applied linguistics, sociology, electrical engineering and biology). Surprisingly, interpersonal interactions tend to be more explicit in papers representing science and more detached in the humanities. Other changes include a greater interdisciplinarity and diversity of disciplines, a swerve towards collaborative research, influence of external sponsors and "the closer connection between career progress and publishing in what is getting to be an extremely competitive market" (p. 105). The final conclusion might be interpreted as another illustration of the impact of neoliberal ideology on academia, leading eventually to the transformations in the conventions of a highly specialised and relatively hermetic field of academic writing.

In the following chapter, Ian Bruce argues for the use of the social cognitive genre model to study the expression of critical thinking in academic and professional writing. The author provides a solid theoretical background and proposes a model of genre analysis, followed by an exemplification of its application and formulation of pedagogical implications. For this reason, the chapter is a highly valuable contribution for ESP/ EAP writing teachers and practitioners.

Academic writing is also explored in Chapter 9, yet this time the authors, Averil Coxhead and Thi Ngoc Yen Dang, focus on the vocabulary of university tutorials and laboratories. They take a critical look at five existing single and multi-word vocabulary lists of academic English, created to support learners and teachers in EAP, and examine their usefulness for students. The results of the undertaken study have clearly illustrated the differences between spoken and written academic language and pointed to the importance of the role played by highfrequency vocabulary in "demonstrating content knowledge" (p. 128) 
in the context of small group spoken interactions. This chapter also offers significant pedagogical implications and guidelines for EAP classroom materials and handbooks development.

In Chapter 10, Janet Holmes draws on the concept of the "culture order" to analyse intercultural workplace interaction. Based on the findings of the "Language in the Workplace Project" (LWP), the scholar illustrates how the culture order affects professional identities and workplace interaction patterns in New Zealand. The author also exemplifies the application of the project findings to the developments of educational materials, both for teachers and learners, prepared to address the needs of newcomers entering the New Zealand job market.

In the final chapter of the second part of the volume, Jean Parkinson scrutinises the modality in the builder's diary - a professional genre adapted for the educational needs of carpentry students to monitor their learning process. Taking into account an observable rise in modality in texts produced by students, the author argues that ESP teachers should enhance the development of their students' visual literacy. In her view, the emphasis should be placed on the meaning created by images as well as rhetorical conventions that make this meaning. Except for providing an insightful comparative analysis of students' builder's diaries that can be successfully applied for training purposes, Parkinson also shows how move analysis might be adapted to incorporate images.

The final, third part of the volume, entitled "Focus on practice" embraces six chapters pertaining to classroom practice, accommodating for a range of issues, including writing personal statements, Data Driven Learning tools, providing online feedback, pragmatic aspects of tutoring and EAP teacher-supervisor collaboration in advanced writing courses.

In the first chapter of Part III of the volume, Ann M. Johns explores the self-promotional genre of Personal Statement (PS), which in her view might pose a challenge not only to students but also native speakers of English "trained to be writers of conventional academic texts" (p. 165). The author analyses the process of PS writing by three Latino students applying for the admission to the University of California (UC) campuses. The chapter opens with a presentation 
of the PS genre and its convention and continues with the discussion of students' challenges while completing the writing task and their responses to them. The whole writing process is divided into three stages labelled by Prior (1998) as transformation, appropriation and externalisation. Johns provides very strong pedagogical implications and concludes her text with detailed proposals for teaching practice.

In Chapter 13, Laurence Anthony, the creator of one the world's most recognised tools for corpus analysis AntConc, developed originally to address specific needs of Japanese learners of EAP, deliberates on the use of Data Driven Learning (DDL) in teaching EAP. Having in mind certain challenges and limitations of DDL, the author makes a strong case for its application in the EAP classroom, which brings tangible results both for teachers and students. On the one hand, DDL is a great help to EAP instructors as it significantly facilitates the preparation of "relevant, discipline-specific material for individual learner" ( $p$. 181). On the other, it enables the learner to work independently with a corpus concerted with their specific needs. In the concluding section of his paper, Anthony presents up-to-the-minute trends in DDL-specific corpus tool development, which involve empowering the learner and getting closer towards processing language at the discourse level (e.g. AntCorGen).

In the subsequent chapter, Lillian Wong discusses practical applications of DDL in the classroom, which turns out to be highly helpful for post-graduate research students. EAP instructors might find this text particularly relevant and useful, as the author provides a detailed description of the applied corpus of highly evaluated postgraduate theses, produced at a range of different faculties at one of the top universities in Hong Kong, and the design of the DDL software that she uses to explore the corpus and prepare DDL learning materials. Additionally, to make the picture complete, the author provides the results of the study on postgraduate students' and teachers' perceptions of the use of electronic reference tools provided by the Hong Kong Graduate Corpus (HKGC) platform and shares implications for teaching.

Jill Northcott in Chapter 15 tackles one of the most recurring issues in teaching EAP, which pertains to the role of EAP versus 
subject specialist in an online academic writing course. According to her study, students' expectations concerning their EAP teachers are not limited to getting language focused feedback but also include feedback on content. These findings go in line with the conclusions of the survey study conducted among undergraduate students by Lankiewicz (2013a). In order to meet students' expectations, Northcott suggests close collaboration of EAP instructors and subject tutors who should learn from each other and trespass the artificial boundaries between language and content.

Ursula Wingate and Eva Ogiermann discuss the role of directives in academic writing peer tutorials. Drawing on their study of a corpus of 10 audio-recorded tutorials delivered by $\mathrm{PhD}$ students, the authors aim to verify whether the tutors tend to take a monologic vs. dialogic teaching approach, which involves, respectively, the assumed use of more or fewer unmitigated directives. Although the findings of the study were not conclusive, the scholars voiced a need to train peer tutors "not so much in the formulation of directives, but in making them the outcome of a dialogue with the student, so that they are coconstructed rather than unilaterally imposed' (p. 238-239). The ideas concerning close cross-interdisciplinary cooperation of EAP instructors and subject teachers in China, spurred by a top-down shift from English for General Purposes towards EAP, recur in the final chapter of the volume, authored by Yongyan Li Margaret Cargill. The scholars reflect on a case study aimed at fostering such cooperation, which revealed certain reluctance towards this idea both on the part of supervisors and students (cf. Lankiewicz 2013a, b).

Among the many positive aspects of the book reviewed, we could mention its very transparent and logical structure, which facilitates navigation. The volume takes a broad view on the field of specialised English and successfully integrates research and practice. It adopts a particularly insightful perspective on the current status of EAP practice, especially in papers taking a critical slant (Chapter 4 and 5 by, respectively, John Flowerdew and Alex Ding), which strike the reader with their pessimistic yet accurate and realistic diagnosis of the field's problems and definitely give the reader food for thought. A definite asset of the publication is the high quality of the studies reported in individual chapters, which provide valuable insights into a range of 
international contexts as well as academic and professional genres. A special mention is also owed to the presentation of the state-of-the-art DDL tools and strategies (Laurence Anthony) and their implementation in the classroom (Lillian L. C. Wong).

Despite its versatility, the book, however, has not entirely managed to provide a satisfactory terminological ordering of the field of specialised English and discourse (cf. Kong 2014), nor has it referred to other competitive nomenclature (e.g. specialised vs. professional, workplace or business English). Delineating the definitions of the terms related to the field, often used interchangeably throughout the volume, would reduce ambiguities and be of great merit to the collection. Due to some editorial errors, the introduction might be a bit misleading for a potential reader as it does not mention Lynne Flowerdew's contribution in Chapter 6 and locates Ann M. Johns's paper in Part II instead of Part III. Some inaccuracies have been also spotted in Chapter 2 (p. 24) in the description of the inner circle of Jane Lockwood's framework (Figure 2.1). These minor drawbacks do not, however, affect the total overwhelmingly positive evaluation of the publication.

On the whole, Specialised English: New directions in ESP and $E A P$ research and practice is a standout volume providing the reader with an idea of what has been done and what could be done in the field of specialised English. It is definitely a recommended read for postgraduate students and researchers in ESP/ EAP as well as ESP/ EAP teachers. Owing to the editors' conscientious selection of contributions, the book reflects the complexity and variability of the flourishing and dynamically developing field. Undoubtedly, it might be found inspirational by researchers and act a springboard for further studies.

\section{References}

FAIRCLOUGH, Norman. 1993. Critical discourse analysis and the marketization of public discourse: the universities. Discourse and Society, 4/2: 133-168.

FOUCAULT, Michel. 1978. The history of sexuality. Vol. 1: An Introduction. New York: Random House.

HOLBOROW, Marnie. 2015. Language and neoliberalism. London/New York: Routledge. 
JENKINS, Jennifer. 2000. The phonology of English as an international language. Oxford: Oxford University Press.

KONG, Kenneth. 2014. Professional discourse. Cambridge: Cambridge University Press.

LANKIEWICZ, Hadrian. 2013a. Filologiczna praca licencjacka a rozwój naukowych kompetencji studenta [The philological BA thesis versus the development of student academic competences]. Neofilolog, 40/1: 111-125.

LANKIEWICZ, Hadrian. 2013b. Taming academic language: Reflections of a methodology teacher. In: SZCZEPANIAK-KOZAK, Anna; LANKIEWICZ, Hadrian. (Eds.). The creative potential of the Word: From fiction to education. Piła: Państwowa Wyższa Szkoła Zawodowa im. Stanisława Staszica w Pile. pp. 123-143.

PRIOR, Paul. 1998. Writing/Disciplinarity: A sociohistoric account of literate activity in the academy. New York: Taylor Francis/LEA.

SEIDLHOFER, Barbara. 2001. Closing a conceptual gap: The case for a description of English as a lingua franca. International Journal of Applied Linguistics, 11: 133-158.

Recebido em: 03/10/2019

Aprovado em: 02/06/2020 